\title{
Effect of holding pressure on densification and mechanical properties of $\mathrm{Cf}_{\mathrm{f}} / \mathrm{Mg}$ composites
}

\author{
X. Wei ${ }^{1}$, L. $\mathrm{Qi}^{*}{ }^{*}, \mathrm{~L} . \mathrm{Ju}^{1}, \mathrm{~W} . \mathrm{Tian}^{1}, \mathrm{X} . \mathrm{Hou}^{2}$ and $\mathrm{H} . \mathrm{Li}^{3}$ \\ ${ }^{1}$ School of Mechanical Engineering, Northwestern Polytechnical University, Xi' an 710072, \\ China \\ ${ }^{2}$ University of Nottingham, University Park, Nottingham NG7 2RD, England \\ ${ }^{3}$ School of Materials Science and Engineering, Northwestern Polytechnical University, Xi'an \\ 710072, China
}

*Corresponding author, email qilehua@nwpu.edu.cn

\begin{abstract}
Carbon fibre reinforced magnesium alloy matrix composites were fabricated by using liquidsolid extrusion directly following vacuum infiltration technique. The experimental results showed that the microstructures of $\mathrm{C}_{\mathrm{f}} / \mathrm{Mg}$ composites depended on the holding pressure. The porosity was reduced gradually, and the densification was improved obviously, respectively, with the increase of the holding pressure. The densification, hardness and Ultimate tensile strength of $\mathrm{C}_{\mathrm{f}} / \mathrm{Mg}$ composites were significantly improved as the holding pressure increased in the range of $0.1-15 \mathrm{MPa}$. The densification was not obvious, but the UTS of the $\mathrm{C}_{\mathrm{f}} / \mathrm{Mg}$ composites decreased gradually as the holding pressure increased in the range of 25-45 MPa. The $\mathrm{C}_{\mathrm{f}} / \mathrm{Mg}$ composites presented a good performance when the holding pressure was about $15 \mathrm{MPa}$.
\end{abstract}

Keywords: Holding pressure, Microstructure, Densification, Mechanical properties, $\mathrm{C}_{\mathrm{f}} / \mathrm{Mg}$ composites 


\section{Introduction}

Carbon fibres have been widely used in various composites for its excellent properties. Carbon fibre reinforced magnesium alloy matrix composites $\left(\mathrm{C}_{\mathrm{f}} / \mathrm{Mg}\right)$ exhibit high specific strength and specific stiffness, low thermal expansion coefficient, which produces a good application prospect in aerospace and automobile field [1-3]. $\mathrm{C}_{\mathrm{f}} / \mathrm{Mg}$ composites can be used as a type of lightweight structural materials to replace the traditional aluminium alloy and magnesium alloy, such as satellite antennas, space mounting plates and optical reflector brackets [4-7] However, the applications of $\mathrm{C}_{\mathrm{f}} / \mathrm{Mg}$ composites are restrained due to the existence of some microscopic defects, which are caused by inappropriate fabrication parameters. Hence, it is necessary to study the correlation between the performance of the $\mathrm{C}_{\mathrm{f}} / \mathrm{Mg}$ composites and the fabrication parameters.

Regarding the fabrication of $\mathrm{C}_{\mathrm{f}} / \mathrm{Mg}$ composites, liquid fabrication method has become a priority due to the economical consideration, therefore the shrinkage of molten magnesium alloy is an important issue [8]. With liquid fabrication method, the preform can be infiltrated by molten magnesium alloy under a certain pressure due to the good liquidity of metal in the molten state. Liquid fabrication method can be categorised into squeeze casting, pressureless infiltration and vacuum pressure infiltration, etc., according to the pressure way [9-11]. In squeeze casting, molten magnesium alloy is exposed to air, so it is easy to introduce entrapped air within the composites [10]. A good wettability between carbon fibres and matrix metal should be required in the pressureless infiltration [11]. Equipment requirements in vacuum pressure infiltration process are more comprehensive and complex compared with other fabrication methods [12]. Liquid-solid extrusion directly following vacuum infiltration (LSEVI) is a special technique that combines the advantages of traditional vacuum infiltration and squeeze casting process, in which magnesium alloy melting, preform 
preheating, vacuum infiltration and liquid-solid extrusion can be integrated in an experiment system [13-15]. crystallised and solidified in the carbon fibre preform under an appropriate pressure. However, the introduction of carbon fibres brings a variation in the densification process of $\mathrm{C}_{\mathrm{f}} / \mathrm{Mg}$ composites [16]. When the infiltration process of molten magnesium alloy in a carbon fibre preform completes, a suitable holding pressure is very critical for promoting the solidification of molten magnesium alloy, reducing the porosity and improving the performance of $\mathrm{C}_{\mathrm{f}} / \mathrm{Mg}$ composites [17]. In order to optimise the pressure-holding process, it is necessary to evaluate the microstructures and mechanical properties of $\mathrm{C}_{\mathrm{f}} / \mathrm{Mg}$ composites under different holding pressures. For the pursuit of high quality metal matrix composites, the fabrication methods have been conducted by many scholars. Lee et al. [18,19] studied the microstructures of the metal matrix composites (MMC), and the experimental results showed that the fine microstructures gave the possibility of improving the material properties of the MMCs. Seong et al [20] carried out the melt infiltration by squeeze casting in processing continuous graphitic fibre reinforced aluminium matrix composites, and a region consisting of coarse dendrites was found in the fibre-free matrix. Sutradhar [21] investigated the solidification characteristics of aluminium alloy matrix composites, and found that the solidification rate was faster in the case of unreinforced matrix alloy. However, the fabrication parameters have to be properly controlled because entrapment and oxidation are more easily occurred in molten magnesium alloy. The excessive pressure can also damage the reinforcement [20]. Hence, it is necessary to study the effect of holding pressure on the performance of $\mathrm{C}_{\mathrm{f}} / \mathrm{Mg}$ composites.

In this paper, $\mathrm{C}_{\mathrm{f}} / \mathrm{Mg}$ composites were fabricated by LSEVI technique with different holding pressures. To optimise the holding pressure, the microstructures, densification process and mechanical properties of $\mathrm{C}_{\mathrm{f}} / \mathrm{Mg}$ composites were investigated. 


\section{Materials and methods}

\section{Materials}

Casting magnesium alloy AZ91D was selected as the matrix material. AZ91D magnesium alloy presented a good liquidity and a wide range of solidification temperature, so it was suitable for the fabrication of $\mathrm{C}_{\mathrm{f}} / \mathrm{Mg}$ composites. The chemical compositions of AZ91D magnesium alloy were $8.30-9.70 \% \mathrm{Al}, 0.35-1.00 \% \mathrm{Zn}, 0.15-0.50 \% \mathrm{Mn}, \leq 0.10 \% \mathrm{Si}$, $\leq 0.03 \% \mathrm{Cu}$ and balance $\mathrm{Mg}$.

Toray T700-12 K carbon fibres were selected as the reinforcements, which had an average diameter of $7 \mu \mathrm{m}$, a density of $1.78 \mathrm{~g} \mathrm{~cm}^{-3}$ and a tensile strength of $3.9 \mathrm{GPa}$. The effective diameter of carbon fibre bundle is $0.65 \mathrm{~mm}$. The preforms were fabricated by the superposition of T700-12k non-woven fabrics with an arrangement of $2 \mathrm{D}-0^{\circ} / 90^{\circ}$, which would be beneficial to maintain structural integrity. The preforms were stitched with carbon fibres bundle along the thickness direction. The volume fraction of the preform was about $40 \%$.

Pyrolytic carbon coating was deposited on the surfaces of carbon fibres to prevent the high temperature oxidation and interface reaction in the fabrication of $\mathrm{C}_{\mathrm{f}} / \mathrm{Mg}$ composites [22]. The thickness of pyrolytic carbon coating was in the range of 200-300 nm.

\section{Methods}

The fabrication of $\mathrm{C}_{\mathrm{f}} / \mathrm{Mg}$ composites was carried out in a forming mould, which was made of the $3 \mathrm{Cr} 2 \mathrm{~W} 8 \mathrm{~V}$ steel. The internal diameter of forming mould was $140 \mathrm{~mm}$. The experimental equipment was shown as Fig. 1. 


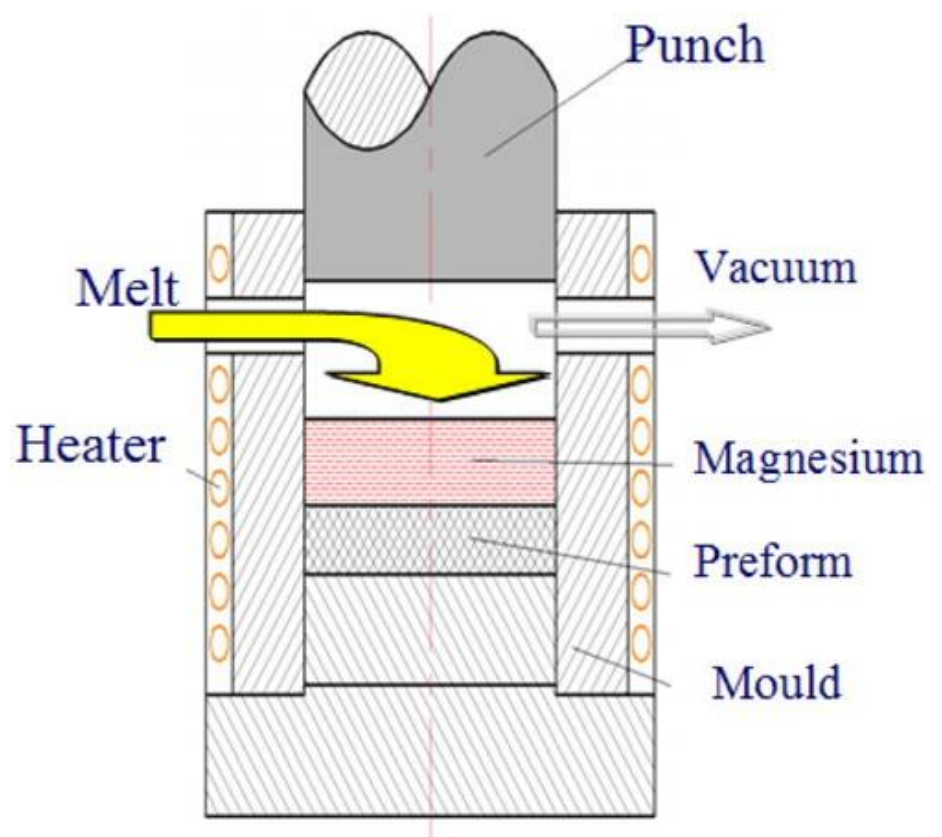

Fig. 1 Schematic diagram of forming mould

The experimental procedures were given as follows: 700-800 g magnesium alloy was melted in a crucible at $720^{\circ} \mathrm{C}$, meanwhile the forming mould was preheated to $595-600^{\circ} \mathrm{C}$, which ensured a good infiltration of the molten magnesium alloy into the carbon fibre preform. The forming mould was persevered at $595-600^{\circ} \mathrm{C}$ for $15-25 \mathrm{~min}$, and then vacuumed by a pump. Next, molten magnesium alloy was poured into the forming mould under a gas pressure of 0.15-0.2 MPa [23]. Infiltration pressure was applied to the surface of the molten magnesium alloy, which was produced by a moving punch connected to a hydraulic press machine (as shown in Fig. 1). In this study, the pressure of $20 \mathrm{MPa}$ was applied to the molten magnesium alloy for conducting the infiltration. Holding pressure was conducted for promoting feeding of the molten magnesium alloy after the infiltration. Different holding pressures were applied by the punch until the magnesium alloy solidified totally as the forming mould temperature decreased to $580^{\circ} \mathrm{C}$. In the case that the pressure was not applied by punch, the holding pressure was considered as $0.1 \mathrm{MPa}$. Finally, $\mathrm{C}_{\mathrm{f}} / \mathrm{Mg}$ composites were removed from the die under room temperature.

\section{Testing}


An optical microscope was used to observe the metallographic microstructures of $\mathrm{C}_{\mathrm{f}} / \mathrm{Mg}$ composites after grinding and polishing. Wolpert 430SVD Vickers hardness tester was used to test the hardness of $\mathrm{C}_{\mathrm{f}} / \mathrm{Mg}$ composites, and the test load was $196 \mathrm{~N}$. Sartorius-CP225D analytical balance with precision of $1 \times 10^{-4} \mathrm{~g}$ was used to test the density based on the Archimedes's principle. UTS tests were conducted on a CMT5304-30KN universal electronic tensile testing machine with the loading rate of $0.5 \mathrm{~mm} \mathrm{~min}^{-1}$, and three tensile samples were tested in each group. Sample test was based on industry standard HB7617-1998. The dimension of the tensile specimens was $75 \mathrm{~mm} \times 10 \mathrm{~mm} \times 2 \mathrm{~mm}$. TESCAN VEGA II scanning electron microscope was used to observe the microstructures and the fracture surfaces of $\mathrm{C}_{\mathrm{f}} / \mathrm{Mg}$ composites. The schematic diagram of sampling range was shown in Fig. 2.

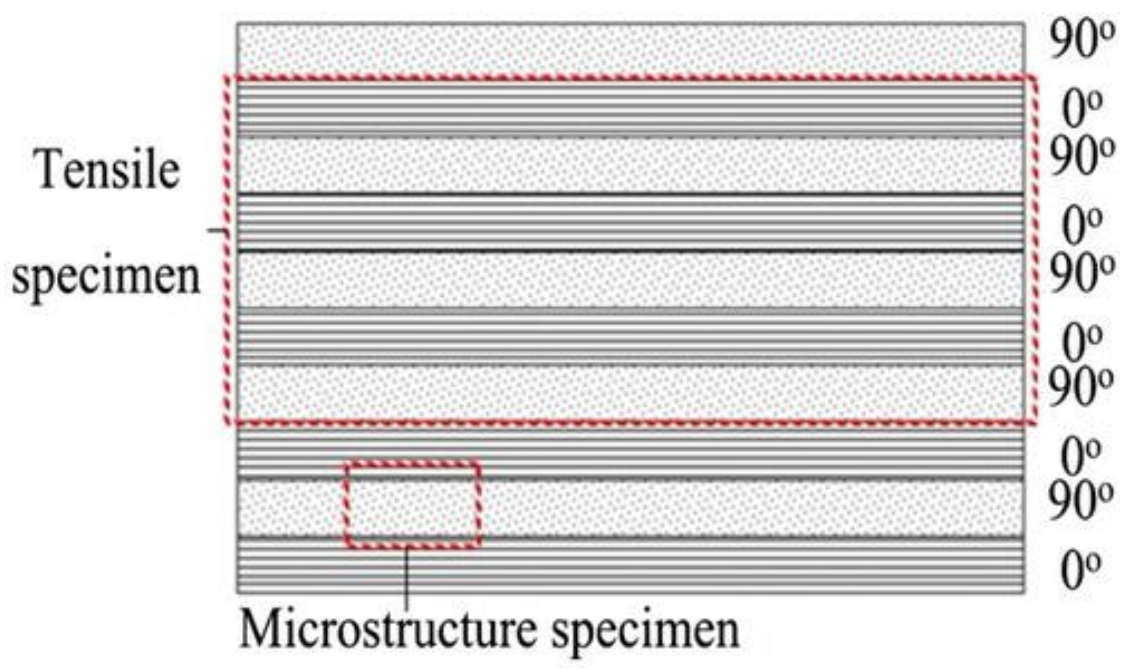

Fig.2 Tensile specimens of $\mathrm{C}_{\mathrm{f}} / \mathrm{Mg}$ composites

\section{Results and discussion}

\section{Effect of holding pressure on the microstructures of $\mathrm{C}_{\mathrm{f}} / \mathrm{Mg}$ composites}

The solidification of the obtained molten $\mathrm{C}_{\mathrm{f}} / \mathrm{Mg}$ composites should be completed under a certain pressure to avoid shrinkage. Figure 3 illustrated the microstructures of $\mathrm{C}_{\mathrm{f}} / \mathrm{Mg}$ 
composites fabricated under different holding pressures, which showed that the magnesium alloy has been infiltrated into the carbon fibre preform completely.
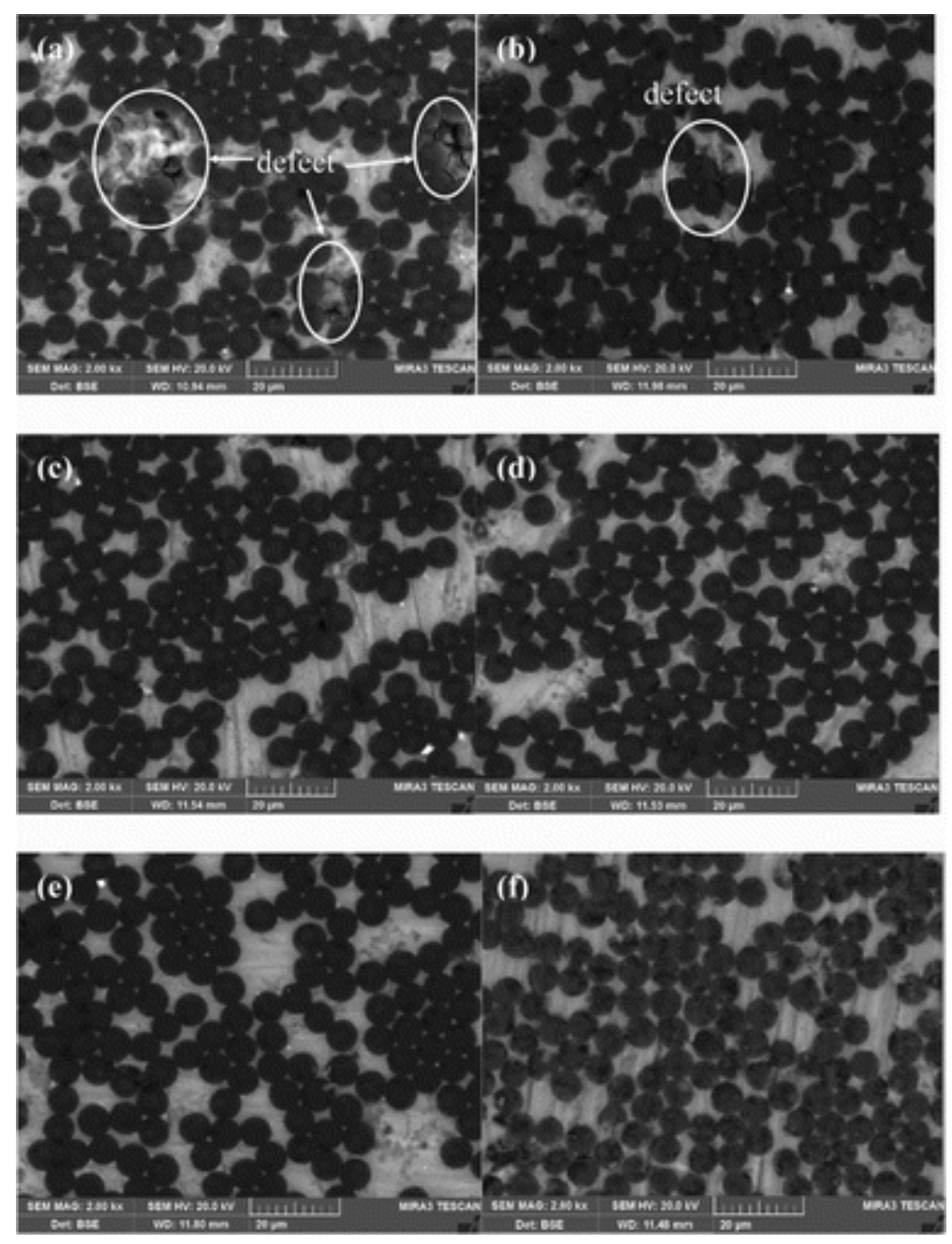

Fig. 3 Microstructures of $\mathrm{C}_{\mathrm{f}} / \mathrm{Mg}$ composites with different holding pressures: (a) $0.1 \mathrm{MPa}$, (b) $5 \mathrm{MPa}$, (c) $15 \mathrm{MPa}$, (d) $25 \mathrm{MPa}$, (e) $35 \mathrm{MPa}$ and (f) $45 \mathrm{MPa}$.

When the holding pressure was $0.1 \mathrm{MPa}$ or low (5 MPa), some shrinkage cracks appeared at the interfaces between the magnesium alloy and carbon fibres, as shown in Fig. $3 a$ and $b$.

Defects were caused by the uneven shrinkage of molten magnesium alloy around the carbon fibres because of the different thermal expansion behaviours of magnesium alloy and carbon fibres. Linear thermal expansion coefficient of T700 carbon fibre was $7 \times 10^{-6} / \mathrm{K}$, while linear shrinkage rate of magnesium alloy was $1.57 \%$ in the solidification process [24]. Then the 
shrinkage defects appeared between carbon fibres due to the lack of holding pressure, which leaded to the micro defects in the $\mathrm{C}_{\mathrm{f}} / \mathrm{Mg}$ composites. Micro cracks reduced or even disappeared gradually with the increase of holding pressure. When the holding pressure was greater than $15 \mathrm{MPa}$, the microstructures of $\mathrm{C}_{\mathrm{f}} / \mathrm{Mg}$ composites were compact, and the microscopic defects and blind angle among carbon fibres have not been found (seen Fig. $3 c-$ f). An appropriate holding pressure could reinforce the bonding between the carbon fibres and magnesium alloy, and prevent the magnesium alloy shrinkage.

The TEM of $\mathrm{C}_{\mathrm{f}} / \mathrm{Mg}$ composite was shown in Fig. 4, which indicated the interface of carbon fibre/matrix was mainly free of carbides. This was due to the fact that the PyC coating served well as an inhibitor of deleterious carbide formation, even if magnesium alloy containing $\mathrm{Al}$ element were used as matrix materials $[22,25]$.

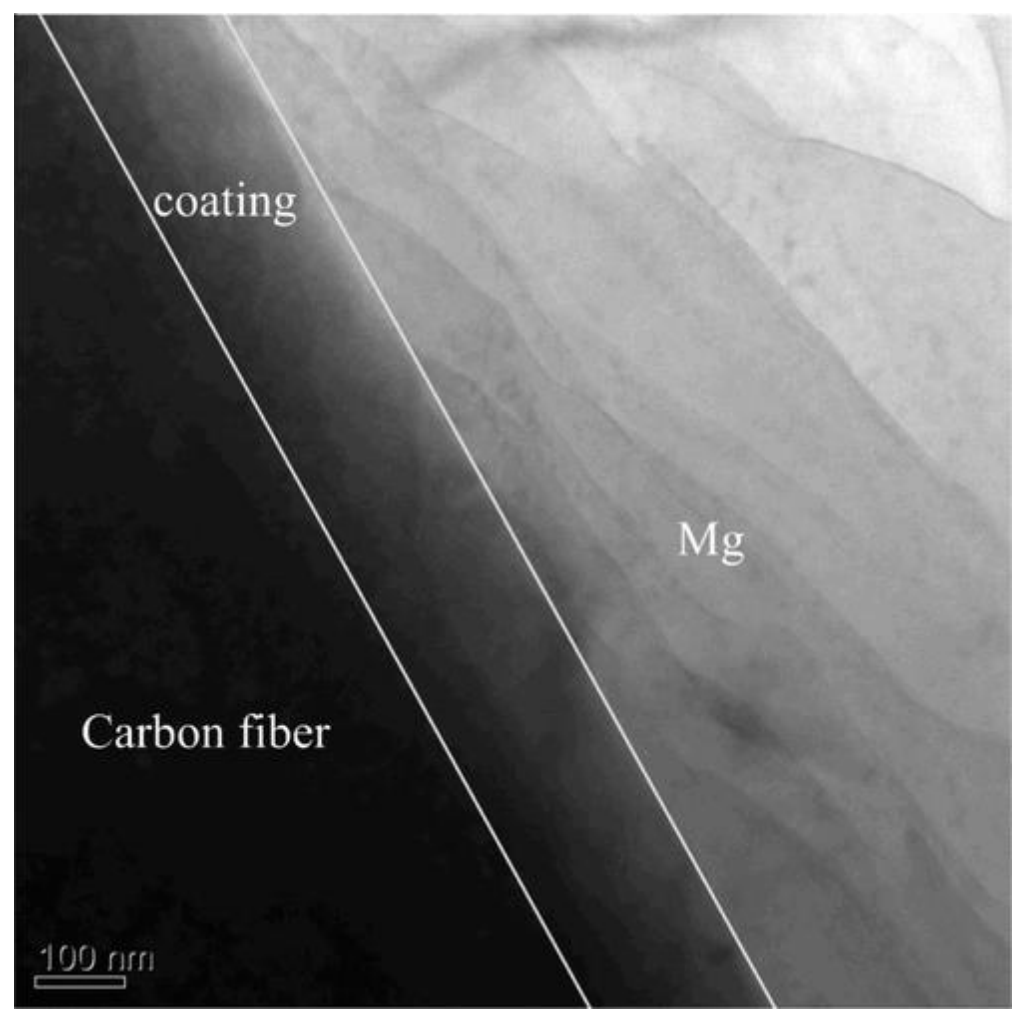

Fig. 4 TEM of $\mathrm{C}_{\mathrm{f}} / \mathrm{Mg}$ composites 


\section{Effect of holding pressure on the densification of $\mathrm{C}_{\mathrm{f}} / \mathrm{Mg}$ composites}

In the densification of the $\mathrm{C}_{\mathrm{f}} / \mathrm{Mg}$ composites, magnesium alloy was in the semisolid state. The densification of the $\mathrm{C}_{\mathrm{f}} / \mathrm{Mg}$ composites increased with the growth of holding pressure until $15 \mathrm{MPa}$, above which the densification was almost constant. The density and hardness of the $\mathrm{C}_{\mathrm{f}} / \mathrm{Mg}$ composites fabricated with different holding pressures were shown in Fig. 5.

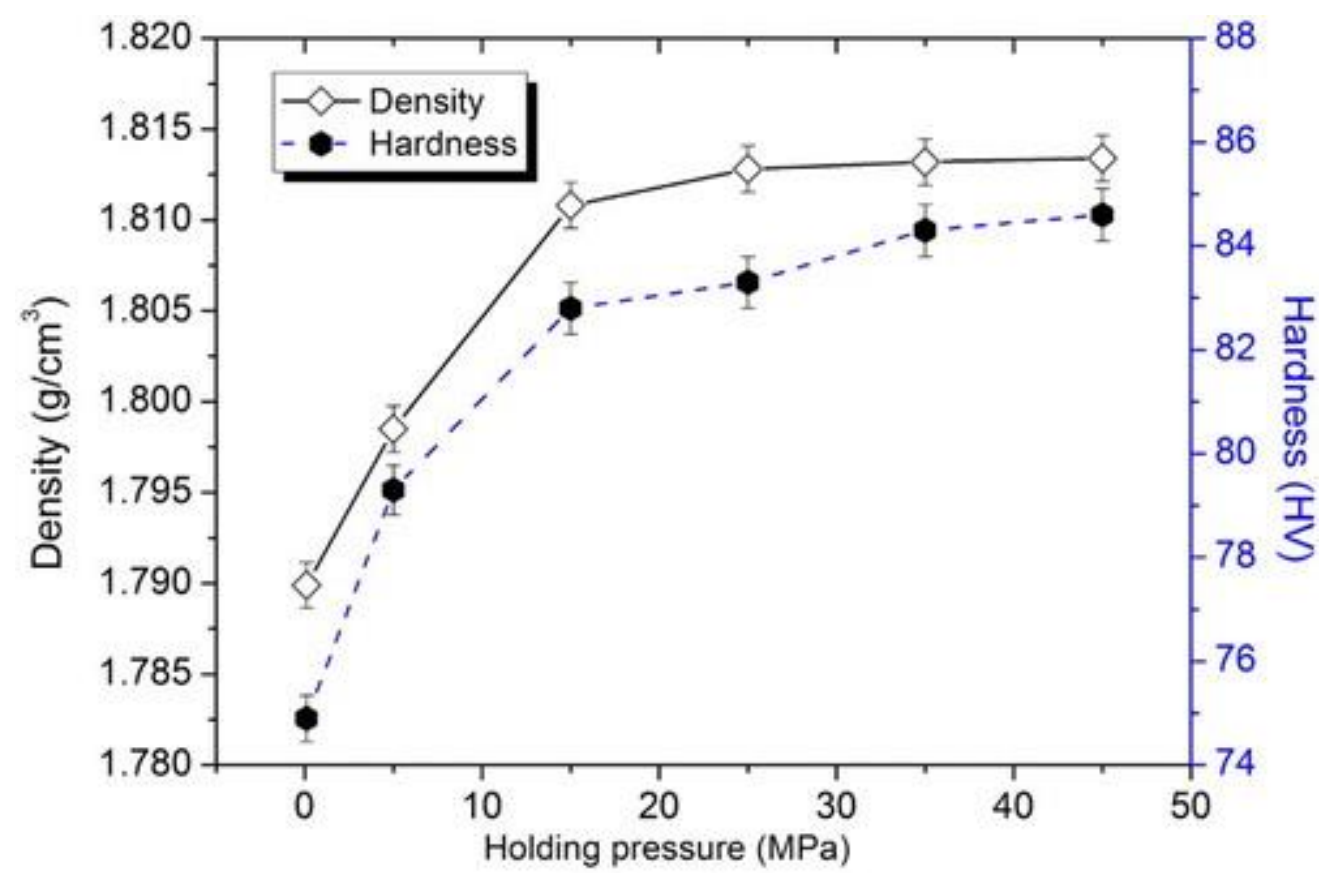

Fig.5 Density and hardness of $\mathrm{C}_{\mathrm{f}} / \mathrm{Mg}$ composites fabricated under the different holding pressures: $a$ densities $b$ hardness

When the $\mathrm{C}_{\mathrm{f}} / \mathrm{Mg}$ composites solidified under the pressure more than $15 \mathrm{MPa}$, the molten magnesium alloy filled the shrinkage in the dendrites, which helped to eliminate the shrinkage. Holding pressure played a critical role in the densification of $\mathrm{C}_{\mathrm{f}} / \mathrm{Mg}$ composite. The increase of holding pressure could inhibit the gas entrapment in molten magnesium alloy and reduce porosity, which could make the density and hardness increase [26].

Based on the microstructures shown in Fig. 2, the density and the hardness, further densification of $\mathrm{C}_{\mathrm{f}} / \mathrm{Mg}$ composites could be less effective when the holding pressure 
exceeded $15 \mathrm{MPa}$. This indicated that $15 \mathrm{MPa}$ was the critical pressure to ensure the complete densification.

\section{Effect of holding pressure on the mechanical properties of the $\mathrm{C}_{\mathrm{f}} / \mathrm{Mg}$ composites}

The UTS of $\mathrm{C}_{\mathrm{f}} / \mathrm{Mg}$ composites was improved compared with that of casting AZ91D (150 $\mathrm{MPa}$ ), and the holding pressure had a significant effect on the mechanical properties of $\mathrm{C}_{\mathrm{f}} / \mathrm{Mg}$ composites. The percentage elongation (2.8-5.4\%) of $\mathrm{C}_{\mathrm{f}} / \mathrm{Mg}$ composites was lower than that of casting AZ91D (8\%). Test results were shown in Table 1.

Table 1 Mechanics performance test results

\begin{tabular}{lcccccc}
\hline Holding pressure $(\mathrm{MPa})$ & 0.1 & 5 & 15 & 25 & 35 & 45 \\
\hline UTS $(\mathrm{MPa})$ & 251 & 307 & 353 & 335 & 287 & 264 \\
\hline Elongation $(\%)$ & 3.9 & 3.2 & 5.4 & 5.2 & 3.6 & 3.8 \\
\hline
\end{tabular}

The mechanical properties and stress-strain curves of $\mathrm{C}_{\mathrm{f}} / \mathrm{Mg}$ composites with different holding pressure were given in Fig. $6 a$ and $b$.

When the holding pressures were 0.1 or $5 \mathrm{MPa}$, the UTS of $\mathrm{C}_{\mathrm{f}} / \mathrm{Mg}$ composites were at a low level due to the existence of micro defects, and the stress-strain curve showed a brittle fracture mode. The increase of UTS was significant when the holding pressures were 15 and $25 \mathrm{MPa}$, which was contributed by the decrease of defects. In the stress-strain curves of the sample fabricated under 15 and $25 \mathrm{MPa}$, when the stress reached a maximum load, the load curves declined sharply due to the breakage of some carbon fibres. Meanwhile, the remaining carbon fibres began to play a load-bearing role and contributed to a small load increase, then the load fell again resulting from the fracture of other carbon fibres. Thus, a step-like fracture surface was produced with the stress cycle and a slight fluctuation in the stress-strain curve was noticed. This fracture mode indicated that the stress concentration was adjusted by the 
interface of $\mathrm{C}_{\mathrm{f}} / \mathrm{Mg}$ composites [27]. When the holding pressures were greater than $35 \mathrm{MPa}$, with the increase of holding pressure, the UTS showed a downward trend, and the characteristics of stress-strain curve were consistent with the curve of low holding pressures. In summary, if the holding pressure was greater than $15 \mathrm{MPa}$, the further holding pressure was not suggested, and it tended to cause ejection force increase and reduce the forming mould life. In order to further determine the influence of holding pressure, the fracture surfaces of $\mathrm{C}_{\mathrm{f}} / \mathrm{Mg}$ composites were observed, as shown in Fig. 7.
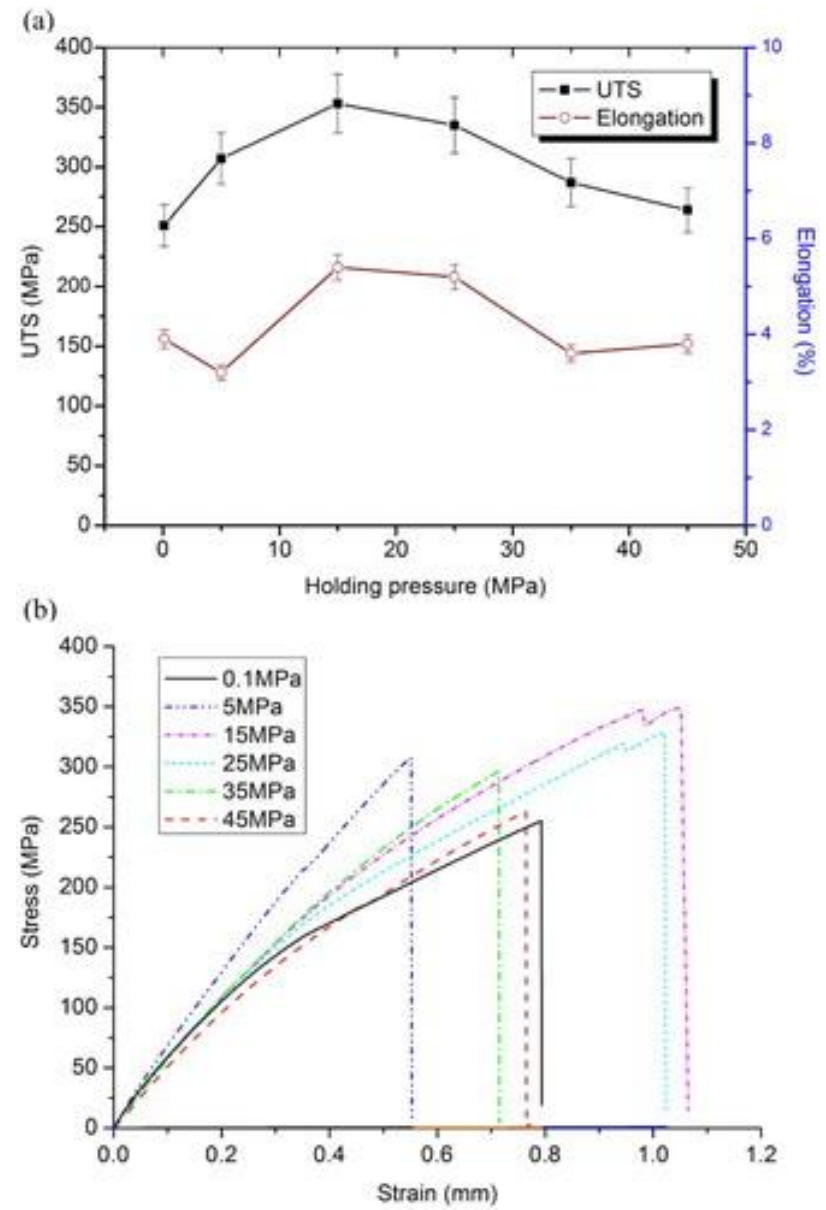

Fig. 6 Mechanical properties and stress-strain curves of $\mathrm{C}_{\mathrm{f}} / \mathrm{Mg}$ composites solidified with different holding pressures: (a) mechanical properties (b) stress-strain curves 

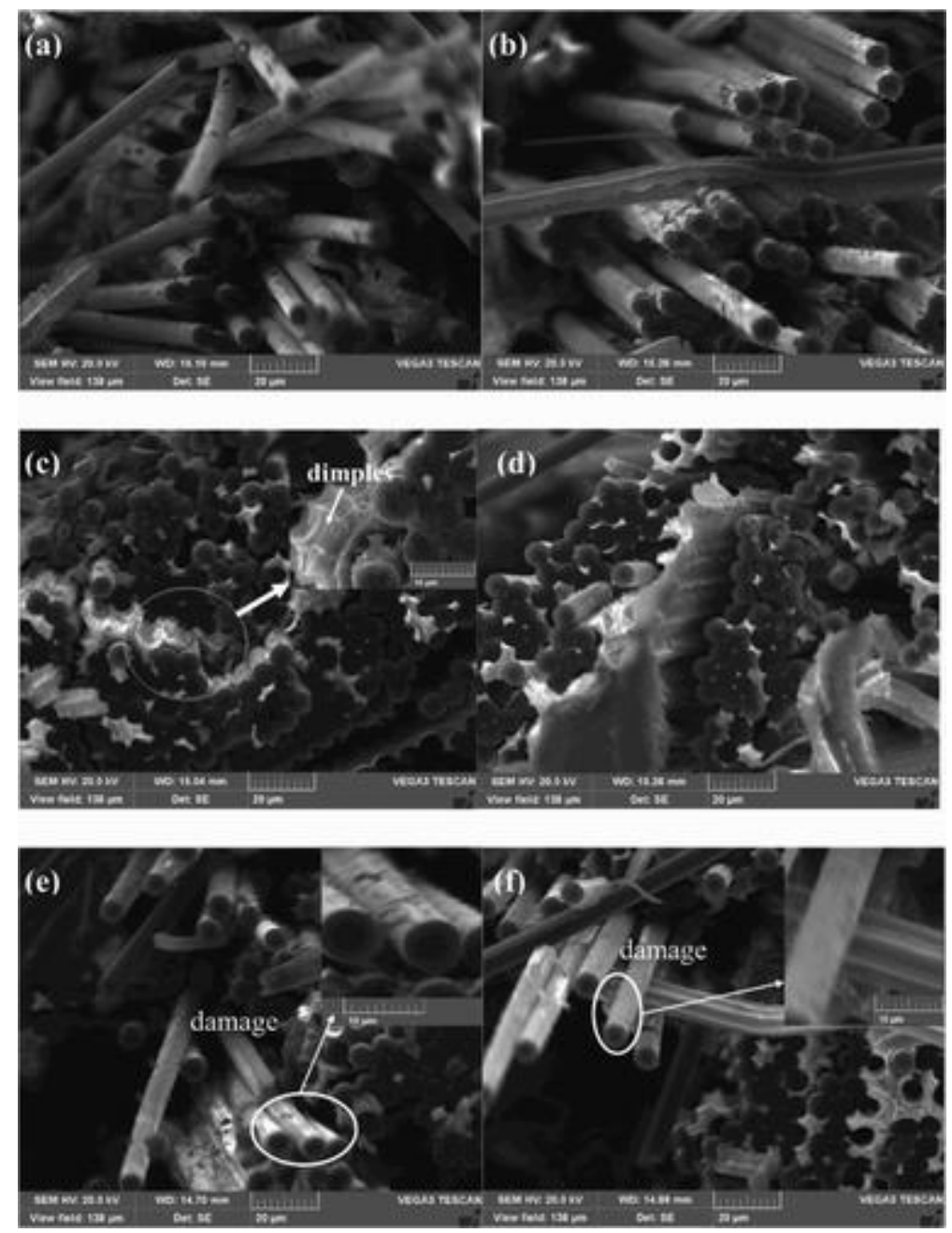

Fig.7 Fracture morphologies of $\mathrm{C}_{\mathrm{f}} / \mathrm{Mg}$ composites with different holding pressures: (a) 0.1 $\mathrm{MPa}$, (b) $5 \mathrm{MPa}$, (c) $15 \mathrm{MPa}$, (d) $25 \mathrm{MPa}$, (e) $35 \mathrm{MPa}$ and (f) $45 \mathrm{MPa}$.

The fracture morphologies of $\mathrm{C}_{\mathrm{f}} / \mathrm{Mg}$ composites were mainly composed of carbon fibre fracture and a small amount of dimples in magnesium alloy [28]. Pull-out of carbon fibres could be observed in Fig. $7 a-f$. In Fig. $7 a$ and $b$, many loose carbon fibres could be seen, and the adjacent carbon fibres were not connected by the matrix. The loose fracture surface was induced by the lack of feeding magnesium alloy, which would cause a poor bonding between carbon fibre and magnesium alloy. The dimples of the magnesium alloy and the debonding between carbon fibres and matrix could be found in Fig. $7 c$ and $d$, which presented an obvious step-like fracture surface. All of these were beneficial to play the full load-carrying role of carbon fibres, which could be seen in the stress-stain curve [29]. The contact angle $\theta$ 
between carbon fibres and molten magnesium alloy was more than $90^{\circ}$, so the solidification interface would be bulged, and the tip of the dendrite growth tendency was located in the space between adjacent carbon fibres [30]. When the holding pressure was too high, the damage on the carbon fibres occurred, which directly reduced the mechanical properties of $\mathrm{C}_{\mathrm{f}} / \mathrm{Mg}$ composite materials [31]. In Fig. $7 e$ and $f$, pyrolytic carbon coating showed partly falling and carbon fibres suffered from obvious damage.

The fracture morphologies analyses also verified that the holding pressure was required to keep in a reasonable value. In order to prevent the damage of carbon fibres in the fabrication of $\mathrm{C}_{\mathrm{f}} / \mathrm{Mg}$ composites, the holding pressure should be controlled about $15 \mathrm{MPa}$.

\section{Conclusions}

The effect of holding pressure on the performance $\mathrm{C}_{\mathrm{f}} / \mathrm{Mg}$ composites was studied, and the following conclusions could be drawn:

1. With the increase of the holding pressure from 0.1 to $15 \mathrm{MPa}$, the porosity in the $\mathrm{C}_{\mathrm{f}} / \mathrm{Mg}$ composites decreased, the microstructure became compact and the density and the hardness significantly increased. When the holding pressure was in the range of 25-45 MPa, the effect of the holding pressure on the densification was slight.

2. The effect of the holding pressure on the performance of $\mathrm{C}_{\mathrm{f}} / \mathrm{Mg}$ composites was complicated. The feeding of magnesium alloy was insufficient when the holding pressure was 0.1 or $5 \mathrm{MPa}$, which leaded to a poor bonding between carbon fibres and matrix metal, so the fracture surface showed as loose characteristics. When the holding pressure was 15 or $25 \mathrm{MPa}$, the fracture surface was an obvious step pattern, and the UTS of the $\mathrm{C}_{\mathrm{f}} / \mathrm{Mg}$ composites could reach $360 \mathrm{MPa}$. When the holding pressure was 35 or $45 \mathrm{MPa}$, the carbon fibre was damaged, and the UTS exerted a 
downward trend. In order to obtain dense and well mechanical prosperities $\mathrm{C}_{\mathrm{f}} / \mathrm{Mg}$ composites, the holding pressure should be about $15 \mathrm{MPa}$ in the fabrication of $\mathrm{C}_{\mathrm{f}} / \mathrm{Mg}$ composites.

\section{Acknowledgement}

This work was supported by the National Nature Science Foundation of China (No. 51472203, 51275417, 51521061), the National High-tech R\&D Program of China (No. 2015AA8011004B), and the 111 project (No. B08040).

\section{References}

[1] A. Bakkar, R. Galun and V. Neubert: 'Microstructural characterisation and corrosion behaviour of laser cladded Al-12Si alloy onto magnesium AS41/carbon fibre composite', Mater. Sci. Technol.-Lond., 2006, 22, (3), 353-362.

[2] S. J. Harris: 'Cast metal matrix composites', Mater. Sci. Technol.-Lond., 1988, 4, 231239.

[3] L. Qi, W. Tian and J. Zhou: 'Homogenization of transverse elastic properties of Cf/Mg composites at an elevated temperature and containing a small fraction of liquid phase', Compos. Sci. Technol., 2015, 117, 234-243.

[4] W. Hufenbach, M. Andrich, A. Langkamp and A. Czulak: 'Fabrication technology and material characterization of carbon fibre reinforced magnesium', J. Mater. Process. Technol., 2006, 175, 218-224.

[5] R. Alderliesten, C. Rans and R. Benedictus: 'The applicability of magnesium based fibre metal laminates in aerospace structures', Compos. Sci. Technol., 2008, 68, (14), $2983-$ 2993.

[6] J. W. Kaczmar, K. Pietrzak and W. Woosinaski: 'The production and application of metal matrix composite materials', J. Mater. Process. Technol., 2000, 106, 58-67.

[7] S. Vaucher, O. Beffort, J. Kubler and F. Lehner: 'An orthotropic magnesium-carbon composite as a lightweight heat-guide material with high specific stiffness and radiation transparency', Adv. Eng. Mater., 2003, 5, (9), 669-672.

[8] H. Z. Ye and X. Y. Liu: 'Review of recent studies in magnesium matrix composites metal-matrix composites for space applications', J. Mater. Sci., 2004, 39, 6153-6171.

[9] S. Sankaranarayanan, M. K. Habibi, S. Jayalakshmi, K. J. Ai, A. Almajid and M. Gupta: 'Nano-AlN particle reinforced Mg composites: microstructural and mechanical properties', Mater. Sci. Technol.-Lond., 2015, 31, (9), 1122-1130. 
[10] L. Chen and Y. Yao: 'Processing, microstructures, and mechanical properties of magnesium matrix composites: a review', J. Acta Metall. Sin. (Engl. Lett.), 2014, 27, (5), $762-774$.

[11] M. H. Stacey: 'Production and characterization of fibres for metal matrix composites', Mater. Sci. Technol.-Lond., 1988, 4, 227-230.

[12] T. Shalu, E. Abhilash and M. A. Joseph: 'Development and characterization of liquid carbon fibre reinforced aluminium matrix composite', J. Mater. Process. Technol., 2009, 209, 4809-4813.

[13] J. Liu, L. H. Qi, J. T. Guan, Y. Q. Ma and J. M. Zhou: 'Compressive behavior of Csf/AZ91D composites by liquid-solid extrusion directly following vacuum infiltration technique', Mater. Sci. Eng. A, 2012, 531, 164-170.

[14] L. Qi, X. Wei, L. Ju, Y. Ma, W. Deng and H. Li: 'Design and application of forming device for the thin-walled Cf/Mg Composite component', J. Mater. Process. Technol., 2016, 238, 459-465.

[15] Y. H. Zhang and G. H. Wu: 'Experimental study on effect of temperature on mechanical properties of graphite fibre reinforced Al matrix composites', Mater. Sci. Technol.-Lond., 2010, 26, (2), 184-187.

[16] J. Shen, W. Yin and Q. Wei: 'Effect of ceramic nanoparticle reinforcements on the Quasistatic and dynamic mechanical properties of magnesium-based metal matrix composites', J. Mater. Res., 2013, 13, (13), 1835-1852.

[17] Y. C. Guan, W. Zhou, H. Y. Zheng and Z. L. Li: 'Solidification microstructure of AZ91D Mg alloy after laser surface melting', Appl. Phys. A, 2010, 101, 339-344.

[18] E. K. Lee, R. S. Amano and P. K. Rohatgi: 'Metal matrix composite solidification in the presence of cooled fibres: numerical simulation and experimental observation', Heat Mass Transfer, 2007, 43, 741-748.

[19] E. K. Lee, R. S. Amano and P. K. Rohatgi: 'Numerical simulation and experimental study of solidification of squeeze cast aluminum composites in the presence of cooled fibres', Heat Mass Transfer, 2007, 44, 71-84.

[20] H. G. Seong, H. F. Lopez, M. Gajdraziska-Josifovska and P. K. Rohatgi: 'Nucleation effects in thermally managed graphite fibre-reinforced Al-Cu and Al-Si composites', Metall. Mater. Trans. A, 2007, 38, 2796-2804.

[21] R. B. G. Sutradhar: 'Solidification characteristics and forgeability of aluminium alloy metal matrix composites', Trans. Indian. Inst. Met., 2012, 65, (4), 355-363.

[22] A. Dorner-Reisel, Y. Nishida, V. Klemm, K. Nestler, G. Marx and E. Müller: 'Investigation of interfacial interaction between uncoated and coated carbon fibres and the magnesium alloy AZ91', Anal. Bioanal. Chem., 2002, 374, 635-638.

[23] J. Guan, L. Qi, J. Liu, J. Zhou and X. Wei: 'Threshold pressure and infiltration behavior of liquid metal into fibrous preform', T. Nonferr. Metal. Soc., 2013, 23, 3173-3179.

[24] Y. Zhang, G. Wu, W. Liu, L. Zhang, S. Pang and W. Ding: 'Preparation and Rheosqueeze casting of semi-solid AZ91-2 wt\% Ca magnesium alloy by gas bubbling process', J. Mater. Res., 2015, 30, (6), 825-832.

[25] S. Kuadela, A. John, S. Baunack and K. Jr. Wetzig: 'A solidworkser spectroscopy study of MgLi melt affected carbon/pyrocarbon fibres', Appl. Surf. Sci., 2001, 179, 129-132. 
[26] R. Etemadi, K. M. Pillai, P. K. Rohatgi and S. A. Hamidi: 'On porosity formation in metal matrix composites made with dual-scale fibre reinforcements using pressure infiltration process', Metall. Mater. Trans. A, 2015, 46, 2119-2133.

[27] F. Wu, J. Zhu, Y. Chen and G. D. Zhang: 'The effects of processing on the microstructures and properties of Gr/Mg composites', Mater. Sci. Eng. A, 2000, 277, (1-2), $143-147$.

[28] S. L. Sin, D. Dube and R. Tremblay: 'An investigation on microstructural and mechanical properties of solid mould investment casting of AZ91D magnesium alloy', Mater. Charact., 2008, 59, 178-187.

[29] W. G. Wang, B. L. Xiao and Z. Y. Ma: 'Evolution of interfacial nanostructures and stress states in mg matrix composites reinforced with coated continuous carbon fibres', $J$. Compos. Sci. Technol., 2012, 72, 152-158.

[30] W. M. Balaba, D. A. Jr. Weirauch, A. J. Perrotta, G. H. Armstrong, P. N. Anyalebechi and S. Kauffman: 'The effect of siloxane spin-on-glass and reaction bonded silicon oxycarbide coatings with a self-propagating interfacial reaction treatment (ASPIRE) in the synthesis of carbon/graphite fibre-reinforced aluminum metal matrix composites', $J$. Mater. Res., 1993, 12, (12), 3192-3201.

[31] H. G. Seong, H. F. Lopez and P. K. Rohatgi: 'Microsegregation during solidification of graphitic fibre-reinforced aluminum alloys under external heat sinks', Metall. Mater. Trans. A, 2007, 38, 138-149. 